\title{
Heat shock response and groEL sequence of Bartonella henselae and Bartonella quintana
}

\author{
David A. Haake, ${ }^{1,2}$ Theresa A. Summers, ${ }^{1}$ Adam M. McCoy ${ }^{1}$ \\ and William Schwartzman ${ }^{3}$ \\ Author for correspondence: David A. Haake. Tel: +1 3104783711 ext. 40267. Fax: +1 3102684928. \\ e-mail: dhaake@ucla.edu
}

\author{
1 Division of Infectious \\ Diseases, 111F West Los \\ Angeles Veterans Affairs \\ Medical Center, Los \\ Angeles, CA 90073, USA \\ 2 Department of \\ Microbiology \& \\ Immunology, UCLA School \\ of Medicine, Los Angeles, \\ CA 90095, USA \\ 3 Division of Infectious \\ Diseases, 111D Sepulveda \\ Veterans Affairs Medical \\ Center, Sepulveda, CA \\ 91343, USA
}

\begin{abstract}
Transmission of Bartonella species from ectoparasites to the mammalian host involves adaptation to thermal and other forms of stress. In order to better understand this process, the heat shock response of Bartonella henselae and Bartonella quintana was studied. Cellular proteins synthesized after shift to higher temperatures were intrinsically labelled with [ ${ }^{35} 5$ ]methionine and analysed by gel electrophoresis and fluorography. The apparent molecular masses of three of the major heat shock proteins produced by the two Bartonella species were virtually identical, migrating at 70, 60 and $10 \mathrm{kDa}$. A fourth major heat shock protein was larger in B. quintana $(20 \mathrm{kDa})$ than in B. henselae (17 kDa). The maximum heat shock response in $B$. quintana and B. henselae was observed at $39^{\circ} \mathrm{C}$ and $42{ }^{\circ} \mathrm{C}$, respectively. The groEL genes of both Bartonella species were amplified, sequenced and compared to other known groEL genes. The phylogenetic tree based on the groEL alignment places B. quintana and B. henselae in a monophyletic group with Bartonella bacilliformis. The deduced amino acid sequences of Bartonella GroEL homologues contain signature sequences that are uniquely shared by members of the Gram-negative $\alpha$-purple subdivision of bacteria, which live within eukaryotic cells. Recombinant $\mathrm{His}_{6}$-GroEL fusion proteins were expressed in Escherichia coli to generate specific rabbit antisera. The GroEL antisera were used to confirm the identity of the $60 \mathrm{kDa}$ Bartonella heat shock protein. These studies provide a foundation for evaluating the role of the heat shock response in the pathogenesis of Bartonella infection.
\end{abstract}

Keywords: heat shock, Bartonella benselae, Bartonella quintana, GroEL

\section{INTRODUCTION}

The genus Bartonella includes organisms formerly classified in the genera Grahamella and Rochalimaea (Brenner et al., 1993; Birtles et al., 1995). Common features of Bartonella species include transmission by an ectoparasitic vector and survival within mammalian reservoirs, usually exploiting an intracellular refuge (Schwartzman, 1996). For example, Bartonella bacilliformis, the causative agent of Oroyo fever, occurs in persons in the Andes mountains exposed to sandfly bites. Human disease caused by $B$. bacilliformis is

The GenBank accession numbers for the groEL nucleotide sequences from Bartonella henselae and Bartonella quintana reported in this paper are U78514 and U78515, respectively. characterized by invasion of erythrocytes and endothelial cells (Reynafarje \& Ramos, 1961). Bartonella henselae, the agent of cat scratch disease, appears to be transmitted from infected cats to humans largely by the cat flea (Higgins et al., 1996; Chomel et al., 1996). The cat serves as a reservoir host for $B$. henselae, and the organism has been found within feline erythrocytes (Kordick \& Breitschwerdt, 1995). Bartonella quintana, the agent of trench fever, is transmitted by the human body louse and has also been reported to be haemotrophic (Weiss \& Moulder, 1984).

Transmission from ectoparasites to a mammalian host requires bacterial mechanisms of adaptation to various stress factors. The bacterial heat shock response consists of upregulated synthesis of a highly conserved group of proteins which presumably enable pathogenic bacteria to adapt to thermal and other forms of stress associated 
with life within a mammalian host. In the case of intraerythrocytic pathogens such as Bartonella species, these additional stresses would include adverse nutritional, $\mathrm{pH}$ and oxidative environments. Two of the components of the heat shock response, GroES (Hsp10) and GroEL (Hsp60), form an oligomeric complex which plays an essential role as a molecular chaperonin in protein-folding, assembly and secretion (Mayhew \& Hartl, 1996). The GroEL family of proteins are also of interest because they are major antigens of a number of pathogenic bacteria, and because of their potential role in an autoimmune reactivity to Tcp-1 ( $\mathrm{T}$-complex polypeptide 1), the eukaryotic homologue of GroEL. The antibody response to bacterial heat shock proteins is predominantly directed towards non-conserved epitopes (Young et al., 1990). However, antibody and Tcell responses towards conserved epitopes have been reported (Lamb et al., 1989; van Eden et al., 1988). In humans with B. bacilliformis infection, GroEL is one of the major antigens recognized by the humoral immune response (Knobloch \& Schreiber, 1990). For these reasons, we have characterized the heat shock response of two Bartonella species, B. henselae and B. quintana. In order to characterize the $60 \mathrm{kDa}$ Bartonella heat shock protein we isolated the groEL genes of these organisms. We found that the deduced amino acid sequences of the Bartonella GroEL proteins contain signature sequences shared by other intracellular bacteria.

\section{METHODS}

Bacterial strains. The type strain of B. henselae, ATCC 49882, was provided by the American Type Culture Collection, Rockville, MD, USA (Brenner et al., 1993; Regnery et al., 1992). A human blood isolate of B. quintana, designated ATCC 51694, was generously provided by David Welch, Oklahoma City, OK, USA (Welch et al., 1992). Stocks were maintained in trypticase soy broth with glycerol at $-70{ }^{\circ} \mathrm{C}$ and cultured at $35^{\circ} \mathrm{C}$ on brucella agar containing $5 \%(\mathrm{v} / \mathrm{v}\rangle$ defibrinated rabbit blood in a $5 \%(\mathrm{v} / \mathrm{v}) \mathrm{CO}_{2}$ environment.

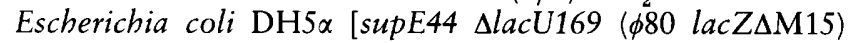
hsdR17 recA1 endA1 gyrA96 thi-1 relA1] was used as the host strain for transformations of recombinant DNA. E. coli strain JM109 [recA1 supE44 endA1 bsdR17 gyrA96 relA1 this(lac-proAB) $\mathrm{F}^{\prime}$ (traD36 proAB lacl $^{9}$ lacZ $\left.\Delta \mathrm{M} 15\right)$ ] was used as the host strain for the pRSET expression vector. E. coli cells were routinely grown in Luria-Bertani (LB) broth or LB agar, unless otherwise noted (Sambrook et al., 1989).

Gel electrophoresis and immunoblotting. Samples for SDSPAGE were solubilized in final sample buffer (FSB) composed of $62.5 \mathrm{mM}$ Tris $/ \mathrm{HCl} \mathrm{pH} 6.8,10 \%$ (v/v) glycerol, $5 \%$ (v/v) 2-mercaptoethanol and 2\%(w/v) SDS. Samples for immunoblots to be probed with GroEL antisera were solubilized in FSB containing $8 \mathrm{M}$ urea. Proteins were separated on a $10 \%$ $(\mathrm{w} / \mathrm{v}$ ) gel with a discontinuous buffer system (Laemmli, 1970) and stained with Coomassie brilliant blue or were transferred to nitrocellulose (Schleicher and Schuell) for immunoblotting. For antigenic detection on immunoblots, the nitrocellulose was blocked with $5 \%(\mathrm{w} / \mathrm{v})$ nonfat dry milk in $0 \cdot 1 \mathrm{M}$ PBS (0.145 M sodium chloride, $0.10 \mathrm{M}$ sodium phosphate) $\mathrm{pH} 7 \cdot 4 / 0 \cdot 1 \%(\mathrm{v} / \mathrm{v})$ Tween 20 (PBS-T), incubated for $1 \mathrm{~h}$ with antiserum diluted 1:5000 (unless otherwise noted) in PBS-T and probed with donkey anti-rabbit antiserum conjugated to horseradish peroxidase (Amersham). Immunoblots containing immunoprecipitated antigens were probed with protein A conjugated to horseradish peroxidase. Antigen-antibody binding was detected using the Enhanced Chemiluminescence system (ECL, Amersham). Blots were incubated in ECL reagents for $1 \mathrm{~min}$ and then exposed to XAR-5 film (Kodak).

Heat shock procedure and radioactive labelling of cell proteins. Bacteria used for heat shock experiments were harvested from solid media and incubated overnight at $35^{\circ} \mathrm{C}$ in $5 \% \mathrm{CO}_{2}$ in liquid medium (Wong et al., 1995). In brief, the liquid medium was prepared with RPMI 1640 (Sigma) and 1\% (v/v) each of L-glutamine (Sigma), HEPES buffer (Sigma), sodium pyruvate (Sigma) and nonessential amino acids (Sigma). Haemin (Sigma) was added to a final concentration of $15 \mathrm{mg} \mathrm{l}^{-1}$. The $\mathrm{pH}$ was adjusted to $7 \cdot 0$ and the medium was filter-sterilized by filtration through a $0.2 \mathrm{~mm}$ filter. After overnight incubation, bacteria were enumerated by serial tenfold dilution and plating on solid media. Bacteria were concentrated by centrifugation at $10000 \mathrm{~g}$ for $10 \mathrm{~min}$ and suspended in labelling medium prepared as described above using RPMI 1640 without methionine. Sets of $1 \mathrm{ml}$ samples of each organism in sterile Eppendorf tubes were incubated at $35^{\circ} \mathrm{C}, 37^{\circ} \mathrm{C}, 39^{\circ} \mathrm{C}$ or $42{ }^{\circ} \mathrm{C}$. Fifteen minutes after the temperature shift, $100 \mu \mathrm{Ci} \quad\left[{ }^{35} \mathrm{~S}\right]$ methionine $\left[10 \mu \mathrm{Ci} \mathrm{m}^{-1}\right.$ $\left(370 \mathrm{kBq} \mathrm{ml}^{-1}\right)$; Amersham] was added to the samples and incubation was continued at the same temperature for another $60 \mathrm{~min}$. The samples were chilled by submersion in an ice water bath, and the cells were then pelleted by centrifugation and washed once in cold $0 \cdot 1 \mathrm{M}$ PBS $\mathrm{pH} 7 \cdot 4$.

Immunoprecipitation of radiolabelled proteins. Samples of radiolabelled $B$. henselae or $B$. quintana cells were resuspended in $1.25 \mathrm{ml} 10 \mathrm{mM}$ Tris $/ \mathrm{HCl} \mathrm{pH} 8.0,10 \mathrm{mM}$ EDTA, $1 \mathrm{mM}$ PMSF. To this suspension was added $12.5 \mu \mathrm{l} 10 \%(\mathrm{v} / \mathrm{v})$ protein-grade Triton X-100 (Calbiochem), followed by gentle agitation for $30 \mathrm{~min}$ at $4{ }^{\circ} \mathrm{C}$. The insoluble material was removed by centrifugation at $16000 \mathrm{~g}$ for $10 \mathrm{~min}$. To the supernatant was added $0.2 \mathrm{ml}$ GroEL antiserum and $0.25 \mathrm{ml}$ of a slurry of staphylococcal protein A-Sepharose CL-4B (Sepharose-SpA; Sigma). The suspension was gently agitated for $1 \mathrm{~h}$. The Sepharose-SpA-antibody-antigen complexes were washed twice in $0.01 \%$ Triton X-100 in $10 \mathrm{mM}$ Tris/HCl $\mathrm{pH} \mathrm{8.0,} \mathrm{and} \mathrm{resuspended} \mathrm{in} \mathrm{FSB.}$

PCR amplification of groEL genes. PCR was used to amplify groEL genes. Synthetic oligonucleotides were prepared using an automated oligonucleotide synthesizer (380B, Applied Biosystems). The $5^{\prime}$-oligonucleotide contained the nucleotide sequence encoding the amino-terminus of $B$. bacilliformis GroEL (GenBank accession number Z15160), including a Bam HI restriction endonuclease site (underlined): 5'-AAA ATG GGA TCC AAA GAA GTN AAR TTY GGN-3'. The 3'oligonucleotide contained the nucleotide sequence encoding the carboxyl-terminus of B. bacilliformis GroEL, including an EcoRI restriction endonuclease site (underlined): 5'-TTT ATG GAA TTC TTA RAA RTC CAT NCC NCC CAT- ${ }^{\prime}$. The groEL gene was amplified in a Programmable Thermal Controller (PTC-100, M. J. Research) with amplification for 30 cycles under standard conditions, using the above synthetic oligonucleotides and Thermus aquaticus polymerase (Promega). Template DNA was prepared by incubating a suspension of bacteria at $100^{\circ} \mathrm{C}$ for $5 \mathrm{~min}$, followed by centrifugation in a microfuge at top speed for $5 \mathrm{~min}$.

DNA sequencing. Standard recombinant DNA procedures were performed as described by Sambrook et al. (1989). 


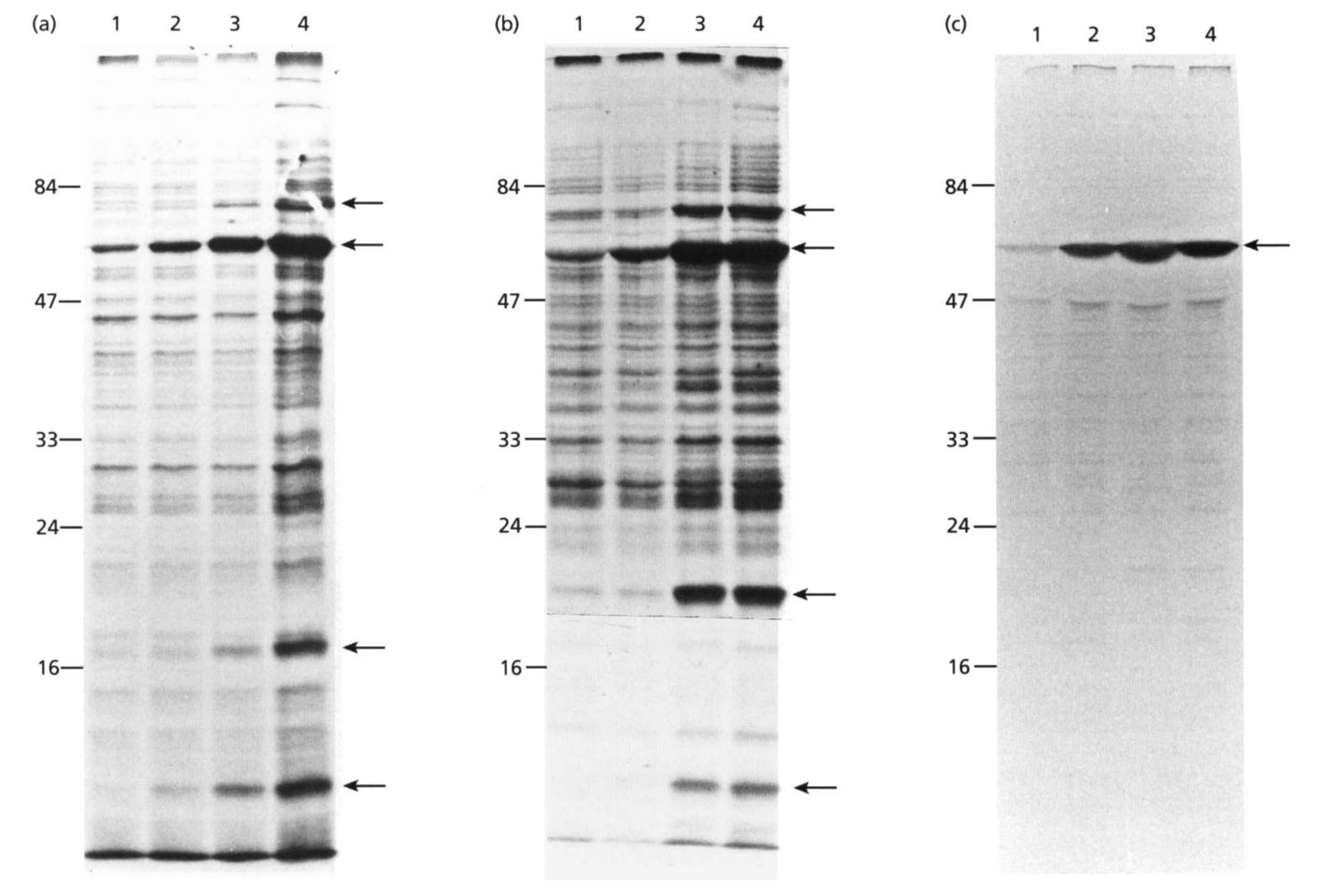

Fig. 1. Fluorogram of $\left[{ }^{35} \mathrm{~S}\right]$ methionine-labelled proteins of $B$. henselae (a), and $B$. quintana (b) at various temperatures. To determine the identity of the $60 \mathrm{kDa}$ heat shock protein, radiolabelled proteins of $B$. henselae (not shown) and $B$. quintana (c) were immunoprecipitated with GroEL antiserum. Lanes: $1,35^{\circ} \mathrm{C} ; 2,37^{\circ} \mathrm{C} ; 3,39^{\circ} \mathrm{C} ; 4,42^{\circ} \mathrm{C}$. Proteins synthesized at a higher level following temperature shift are indicated by arrows. Locations of molecular mass standards are indicated on the left in kDa.

Restriction endonuclease digests were performed as recommended by the suppliers (New England Biolabs and Promega). Based upon statistical considerations, direct sequencing of PCR-amplified DNA should not result in errors (Rao, 1994). Therefore, the amplified DNA was directly sequenced using as sequencing primers the two degenerate oligonucleotide PCR primers (described above) and the following three olignucleotides: GroEL-1, 5'-ATGAACCCAATGGATCTC-3'; GroEL2, 5'-TCGCTGGAAGATGTGGAAGGTG-3'; GroEL-3, 5'TTCAAGGCATCATCAAC-3'. The amplified groEL genes were also sequenced after cloning into pBluescript $\mathrm{KS}(+)$ and transformation into $E$. coli DH5 $\alpha$. DNA sequencing was performed at the UCLA Core DNA Sequencing Facility by the dideoxy chain-termination method with fluorescein-labelled dideoxy nucleotides (Applied Biosystems). DNA sequence information was analysed by the DNA Strider program (Marck, 1988).

Generation of GroEL antisera. The amplified groEL gene was ligated into pRSET (Invitrogen) after digestion with BamHI and EcoRI and transformed into E. coli JM109. The resulting construct, pRSET-groEL, was transformed into E. coli JM109. Expression of the His6-GroEL fusion protein was achieved by IPTG (Sigma) induction followed by infection with M13/T7 phage containing the T7 polymerase gene driven by the E. coli lac promoter. The His6-GroEL fusion protein was purified by affinity chromatography using $\mathrm{Ni}$ NTA-Agarose (Qiagen) and analysed by SDS-PAGE. The His6-GroEL band containing $50 \mu \mathrm{g}$ protein was cut out of the acrylamide gel, dessicated, ground to powder, mixed with Freund's complete adjuvant and inoculated subcutaneously and intramuscularly into a New Zealand White male rabbit. The secondary immunization was given 4 weeks after the primary immunization, using His6-GroEL protein prepared in the same way, mixed with incomplete Freund's adjuvant. The rabbit was bled 2 weeks after the secondary immunization.

\section{RESULTS}

\section{Characterization of the heat shock response of Bartonella species}

Under the conditions used in these experiments, active protein synthesis was found to be occurring in both $B$. benselae and $B$. quintana with incorporation of $\left[{ }^{35} \mathrm{~S}\right]$ methionine into a large number of different proteins. 
Bh ATGGCTGCTAAAGAAGTGAAGTTTGGCCGTGAAGCGCGTGAGCGTTTGTTGCGCGGCGTTGATATCCTTGCTAACGCTGTTAAAGTAACACTCGGCCCTA Bq ATGGCTGCTAAAGAAGTCAAGTTCGGCCGTGAAGCGCGTGAGCGTTTGTTGCGCGGCGTTGATATCCTTGCTAACGCTGTTAAAGTAACGCTCGGCCCTA
$--.-1 .-$
*

Bh AAGGGCGCAATGTGGTGATCGATAAATCATTTGGTGCGCCTCGCATTACAAAAGATGGTGTATCCGTTGCAAAAGAAATCGAACTGGAAGATAAGTTCGA Bq AAGGTCGCAATGTTGTAATTGATAAATCGTTTGGTGCGCCTCGCATCACAAAAGATGGTGTATCTGTTGCAAAAGAAATCGAACTTGAAGATAAGTTTGA
$\star \star \star \star$
*

200

Bh AAATATGGGTGCGCAAATGTTGCGTGAAGTTGCTTCTAAAACCAATGACATTGCTGGTGATGGAACAACAACGGCAACTGTTTTAGGACAGGCTATTGTC Bq AAATATGGGTGCGCAAATGTTGCGCGAAGTTGCTTCTAAAACCAATGACATTGCTGGgGATGGAACAACAACTGCAACTGTTTTAGGACAGGCTATTGTA

Bh CAAGAAGGTGTAAAAGCCGTTGCTGCAGGCATGAACCCAATGGATCTCAAACGTGGTATCGATGCTGCTGTTGATGAAGTGGTGGCAAATCTTTTCAAAA Bq CAAGAAGGGGTGAAAGCCGTTGCTGCTGGCATGAACCCAATGGATCTCAAACGCGGGATTGATGCTGCTGTTGAAGAAGTGGTGGGTAATCTTTTCAAAA $\star \star$

Bh AAGCGAAAAAAATCCAAACTTCAGCAGAAATTGCACAAGTGGGAACAATTTCCGCTAATGGTGCTGCTGAAATCGGCAAAATGATCGCTGATGCCATGGA Bq AAGCGAAAAAAATCCAGACTTCAGCAGAAATTGCACAAGTGGGAACAATTTCCGCCAATGGTGCTGCAGAAATCGGTAAAATGATCGCTGATGCTATGGA *

Bh AAAAGTTGGCAATGAAGGTGTCATTACCGTTGAAGAAGCAAAAACTGCTGAAACGGAATTAGAAGTCGTTGAAGGAATGCAGTTTGATCGTGGATATCTT Bq AAAAGTTGGCAATGAAGGCGTTATCACCGTGGAAGAAGCGAAAACTGCTGAAACGGAATTGGAAGTCGTTGAAGGGATGCAATTCGACCGTGGATATCTT * * * * * * * *

Bh TCCCCTTACTTTGTCACCAATGCTGAGAAAATGGTGGCTGATCTTGATGATCCTTACATTCTTATTCACGAAAAGAAACTCTCTAATCTCCAATCCTTGC Bq TCCCCTTATTTCGTCACCAATGCTGATAAAATGGTGGCTGATCTCGACGATCCTTACATCCTCATTCACGAAAAGAAATTGTCTAATTTGCAATCCTTGC
$\star \quad$ *
$\Delta$
$\star \quad \star$
* *
*
* *

Bh TTCCAGTACTTGAAGCTGTTGTTCAGTCTGGTAAACCACTTCTCATTATCGCTGAAGATGTGGAAGGTGAAGCTTTGGCAACGCTCGTTGTCAACAAACT Bq TTCCAGTGCTCGAAGCTGTTGTTCAGTCTGGCAAACCTCTTCTTATTATCGCTGAAGATGTGGAAGGTGAGGCTTTGGCAACGCTCGTTGTTAACAAGCT * *

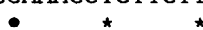

Bh GCGTGGTGGTTTGAAAATTGCTGCTGTGAAAGCTCCAGGATTTGGTGATCGCCGTAAAGCCATGTTAGAAGATATTGCAATCTTAACATCCGGACAGGTT Bq GCGCGGTGGTTTGAAAATTGCTGCTGTGAAAGCTCCAGGATTTGGTGATCGCCGTAAAGCCATGTTGGAAGATATTGCAATCTTGACATCGGGTCAGGTT

Bh ATTTCTGAAGATGTTGGCATTAAATTGGAAAATGTCACTTTGGATATGCTTGGTCGTGCAAAGAAAGTCAATATTTCTAAAGAAAATACCACGATTATTG 1000 Bg ATTTCTGAAGATGTTGGCATTAAATTAGAAAATTTACTTTGGATATGCTTGGTCGTGCGAAGAAAGTGAATATTCTAAAGAAAATACGACGATTATTG

Bh ATGGTGCTGGACAAAAGAGCGAAATTAATGCGCGCGTCAACCAAATCAAGGTACAGATCGAAGAAACAACTTCTGACTATGACCGTGAAAAATTGCAAGA 1100 Bq ATGGTGCTGGGAAAAAAGCTGAAATTAATGCACGCGTAAACCAAATCAAGgTACAGATCGAAGAAACAACTTCTGACTATGACCGTGAAAAATTGCAAGA $\star \Delta \quad \star \Delta \Delta^{\star}$

Bh AAGACTTGCTAAACTCGCTGGAGGTGTTGCTGTTATCCGTGTTGGTGGAGCAACAGAAGTTGAAGTGAAAGAAAAGAAAGATCGTGTTGATGATGCCTTG 1200 Bq AAGACTTGCTAAACTCGCTGGTGGTGTTGCTGTTATCCGTGTTGGTGGTGCGACAGAAGTTGAAGTGAAAGAAAAGAAGGATCGGGTTGATGATGCCTTG * * * * $\quad$ *

Bh AACGCAACACGTGCAGCTGTGGAAGAAGGTATTGTTGCCGGTGGTGGAACCGCATTGTTGCGTGCAGCAAATGCCCTGACTGTTAAAGGAAGCAATCCTG 1300 Bq AATGCAACACGTGCAGCTGTGGAAGAGGGTATTGTTGCCGGTGGTGGAACTGCATTGTTGCGTGCTGCAAATGCCTTGGCAATTAAAGGAAGCAATCCTG

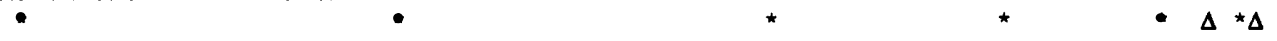

Bh ATCAGGAAGCTGGTATCAATATTGTTCGTCGTGCACTCCAAGCGCCAGCACGCCAAATTGCTACCAATGCCGGTGAAGAAGCAGCGATTATCGTTGGCAA 1400 Bq ATCAAGAAGCTGGTATCAATATTGTTCGTCGTGCACTACAGGCACCAGCACGCCAAATTGCAACTAATGCAGGTGAAGAAGCAGCGATTATCGTTGGCAA *

Bh AGTGCTTGAAAACAATGCAGATACATTTGGTTACAACACCGCAACCGGTGAATTTGGTGATTTGATTGCTTTGGGAATCGTTGATCCTGTGAAGGTTGTG 1500 Bq AGTGCTTGAAAATAACGCAGATACATTTGGTTACAATACCGCAACTGGTCAATTTGGTGATTTGATTGCTTTAGGAATCGTTGATCCTGTGAAGGTTGTG

$$
\text { * * } * \quad \text { * } \triangle
$$

Bh CGCTCTGCTCTTCAGAATGCTGCCTCAATTGCTAGCCTTCTCATTACAACAGAAGCAATGGTTGCTGAAGTTCCAAAGAAAGACACACCAGTGCCTCCAA 1600 Bq CGTTCTGCTCTCCAGAATGCTGCATCGATTGCCAGCCTTCTCATCACAACAGAAGCAATGGTTGCTGAAGTTCCAAAGAAAGACACTCCAATGCCTCCAA

Bh TGCCTGGTGGCGGAATGGGTGGAATGGGCGGCATGGACTTCTAA Bq TGCCTGGTGGCGGAATGGGTGGAATGGGCGGAATGGACTTCTAA

1644

Fig. 2. Nucleotide sequences of the groEL genes of $B$. henselae (Bh) and B. quintana (Bq). Underlined sections of the sequences indicate locations of the degenerate oligonucleotide primers used to amplify the groEL genes. Asterisks indicate locations of silent nucleotide differences. Triangles indicate location of nucleotide differences that result in amino acid substitutions. Dashes indicate location of sequence data predicted from groEL genes of related organisms. 


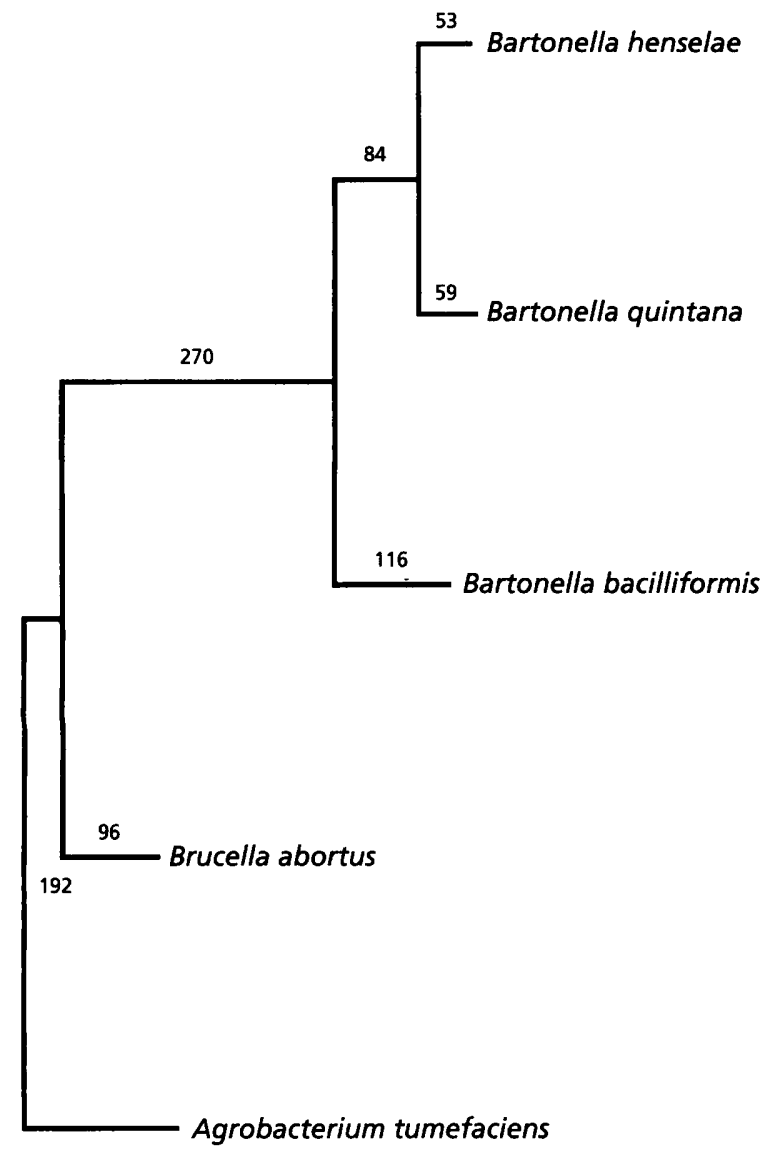

Fig. 3. Phylogenetic tree based on nucleotide sequence differences of the groEL sequences of $B$. henselae (this work), $B$. quintana (this work), $B$. bacilliformis (GenBank accession number Z15160), Brucella abortus (Gor \& Mayfield, 1992; GenBank accession number M83930) and Agrobacterium tumefaciens (Segal \& Ron, 1993; GenBank accession number $X 68263$ ). The tree places $B$. quintana and $B$. henselae in a monophyletic group with $B$. bacilliformis. Sequences were analysed using the PAUP software package (version 3.1; D. Swafford, Smithsonian Institution, Washington, DC, USA). Horizontal lengths are proportional to nucleotide step differences (indicated above lines).

Both organisms exhibited a heat shock response, with a subset of proteins that were synthesized at a distinctly higher level at temperatures above $37^{\circ} \mathrm{C}$. In B. henselae there was an increase in synthesis of proteins with apparent molecular masses of $70,60,17$ and $10 \mathrm{kDa}$ (Fig. 1a). While there were numerous differences between the protein synthesis profiles of the two organisms, the heat shock response of $B$. quintana was very similar to that of $B$. henselae, except that instead of a $17 \mathrm{kDa}$ protein, a $20 \mathrm{kDa}$ major heat shock protein was synthesized (Fig. 1b). The molecular masses of all four major heat shock proteins of B. quintana are similar to those of Brucella abortus (Lin et al., 1992). We confirmed the identity of the $60 \mathrm{kDa}$ proteins of $B$. henselae (data not shown) and B. quintana (Fig. 1c) by selective recovery of the $60 \mathrm{kDa}$ proteins by immunoprecipitation with our rabbit polyclonal GroEL antisera. Based on their apparent molecular masses, it is possible to tentatively identify two of the other Bartonella species heat shock proteins as DnaK $(70 \mathrm{kDa})$ and $\mathrm{Hsp} 10$ (i.e. GroES) $(10 \mathrm{kDa})$.

\section{Sequence analysis of groEL genes from Bartonella species}

Use of either B. henselae or B. quintana DNA in PCR with the groEL primers resulted in a single amplicon. Comparison of the two amplified groEL DNA sequences revealed $93.7 \%$ DNA sequence identity (103/1644 nucleotide differences). As shown in Fig. 2, three of these nucleotide differences were found at degenerate positions of the oligonucleotide PCR primers. Most of the DNA sequence differences were silent: as shown in Fig. 2, only 10 out of 107 nucleotide differences would result in amino acid substitutions. Several regions of the groEL sequence had a high concentration of nucleotide differences allowing identification of variable regions potentially useful in Bartonella species identification. The groEL sequences of $B$. henselae and $B$. quintana were aligned with those of several related bacteria to perform phylogenetic analysis. The resulting phylogenetic tree shown in Fig. 3 was very similar to that based on rRNA sequence alignment (Brenner et al., 1993).

The deduced amino acid sequences of the GroEL proteins of $B$. benselae and $B$. quintana were aligned with those of the GroEL proteins of several related bacteria (Fig. 4). There was a high degree of GroEL sequence conservation within the Bartonella genus. The sequence of $B$. quintana GroEL was more similar to that of $B$. henselae than to the only other Bartonella GroEL sequence known, that of $B$. bacilliformis. $B$. quintana GroEL exhibited $98.4 \%$ sequence identity with $B$. henselae GroEL and $90.9 \%$ sequence identity with $B$. bacilliformis GroEL. There was also considerable similarity with GroEL sequences of other $\alpha$-purple bacteria, such as Brucella abortus $(86.3 \%$ identical) and Agrobacterium tumefaciens $(81.4 \%)$. This pattern of GroEL amino acid sequence relatedness is reflected in the phylogenetic tree constructed using groEL sequences (Fig. 3).

The groEL sequences reported here are two of the first transcribed genes to be sequenced in these two Bartonella species; others include the $B$. henselae genes encoding citrate synthase (Norman et al., 1995) and the $17 \mathrm{kDa}$ antigen (Anderson et al., 1995). Since GroEL is highly expressed, it is reasonable to assume that the groEL genes are representative of the preferred codon usage for optimal translation in these bacteria. The $\mathrm{G}+\mathrm{C}$ content of the groEL genes of $B$. henselae and $B$. quintana was found to be $44.3 \mathrm{~mol} \%$ and $44.5 \mathrm{~mol} \%$, respectively, reflecting the low $\mathrm{G}+\mathrm{C}$ content of the genomes of these bacteria $(41.0 \mathrm{~mol} \%$ and $40.3 \mathrm{~mol} \%$, respectively) (Daly et al., 1993). As expected, B. henselae 
Bq MAAKEVKFGREARERLLRGVDILANAVKVTLGPKGRNVVIDKSFGAPRITKDGVSVAKEIELEDKFENMG

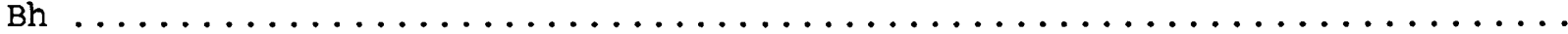

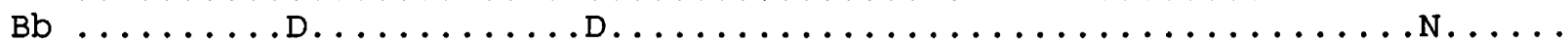

$\mathrm{Ba} \ldots \mathrm{D} \ldots \ldots \mathrm{T} \ldots \mathrm{KM} \ldots \ldots \ldots \mathrm{D} \ldots \ldots \ldots \mathrm{A}-\ldots \ldots \mathrm{E} \ldots \ldots \ldots \ldots \ldots$

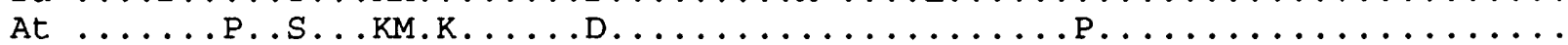

Bq AHMLREVASKTNDIAGDGTTTATVLGHAIVHEGVKAVAAGMNPMDLKRGIDAAVEEVVGNLFKKAKKIHT 140

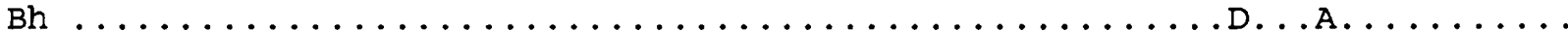

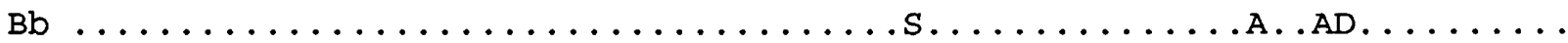

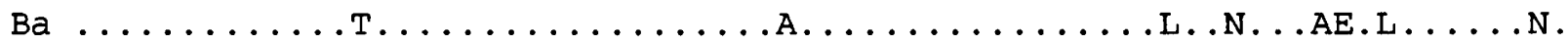

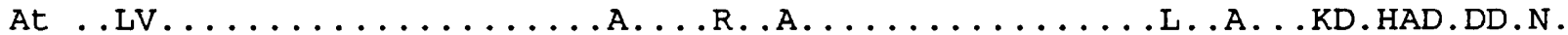

Bq SAEIAHVGTISANGAAEIGKMIADAMEKVGNEGVITVEEAKTAETELEVVEGMHFDRGYLSPYFVTNADK 210

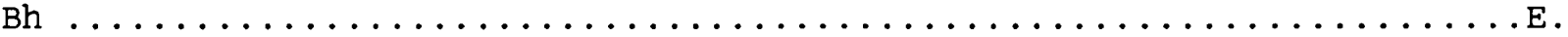

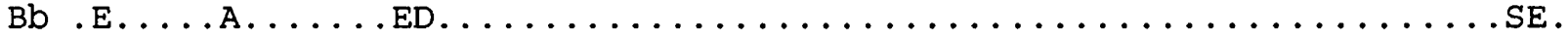

$\mathrm{Ba} . \mathrm{E} . \mathrm{V} \ldots \ldots \ldots \ldots-. \mathrm{KH} \ldots \ldots . \mathrm{E} \ldots \mathrm{H} \ldots \ldots \ldots \ldots \ldots \ldots \ldots \ldots \ldots \ldots$

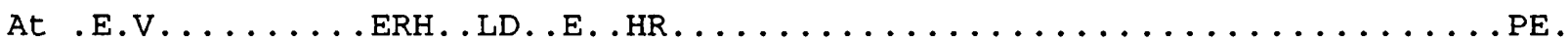

Bq MVADLDDPYILIQEKKLSNLHSLLPVLEAVVHSGKPLLIIAEDVEGEALATLVVNKLRGGLKIAAVKAPG

$\mathrm{Bh}$

$\mathrm{Bb}$

$\mathrm{Ba}$

At

$\mathrm{Bq}$

$\mathrm{Bh}$

$\mathrm{Bb}$

$\mathrm{Ba}$

At

$\mathrm{Bq}$

$\mathrm{Bh}$

$\mathrm{Bb}$

$\mathrm{Ba}$

At

$\mathrm{MV} \ldots \ldots \ldots \ldots \ldots$

....E.A...L......AM....... . . . .

. R.

FGDRRKAMLEDIAILTSGHVISEDVGIKLENVTLDMLGRAKKVNISKENTTIIDGAGKKAEINARVNHIK 350

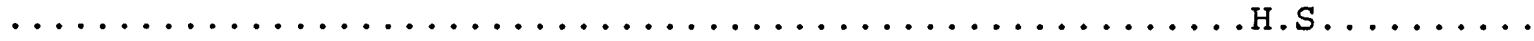

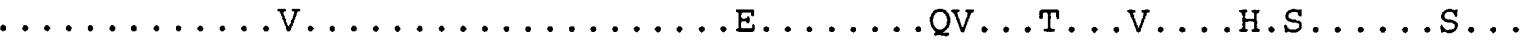

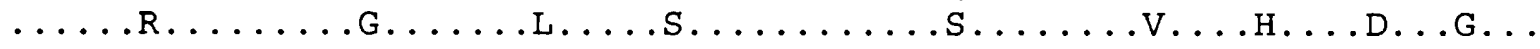

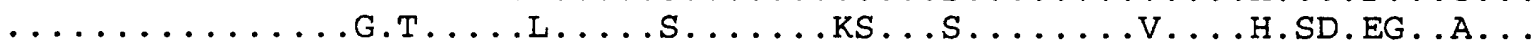

VHIEETTSDYDREKLHERLAKLAGGVAVIRVGGATEVEVKEKKDRVDDALNATRAAVEEGIVAGGGTALL 420

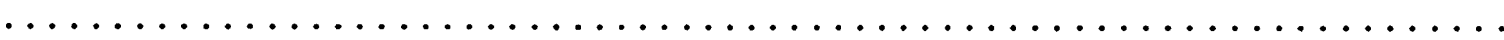

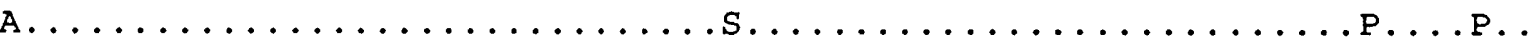

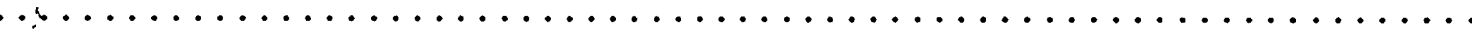

Bq RAANALAIKGSNPDHEAGINIVRRALHAPARHIATNAGEEAAIIVGKVLENNADTFGYNTATGHFGDLIA 490

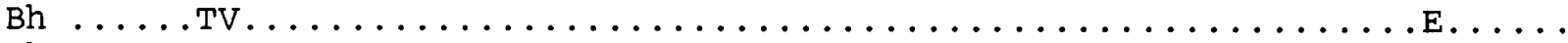

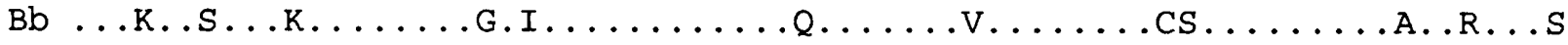

$\mathrm{Ba} \ldots$ STKITA..V.A............................TSE.......EY...S

At .SSTKITV..V.D........K...LSV....E..D..S.V...I.DK.E.NY...AH..EY....

Bq LGIVDPVKVVRSALHNAASIASLLITTEAMVAEVPKKDTPMPPMPGGGMGGMGGMDF 548

$\mathrm{Bh} \ldots \ldots \ldots \ldots \ldots \ldots \ldots \ldots \ldots \ldots \ldots \ldots$

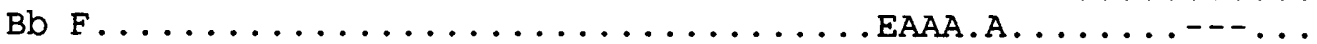

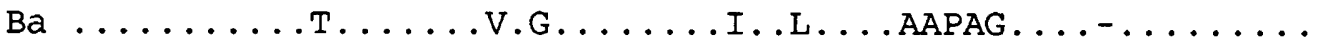

At $\mathrm{L} \ldots \ldots \ldots$.........V.V. ........L...ESA..H..........

Fig. 4. Alignment of the predicted GroEL amino acid sequences using the CLUSTAL program (Higgins \& Sharp, 1988). Sequences aligned were those of $B$. quintana $(\mathrm{Bq}), B$. henselae (Bh), B. bacilliformis (Bb), Brucella abortus (Ba) and Agrobacterium tumefaciens (At). GenBank accession numbers and references for the sequences are given in the legend to Fig. 3. Dots indicate residues identical to those present in the top row. Dashes indicate gaps introduced to maximize alignment.

and $B$. quintana have a preference for codons with an $\mathrm{A}$ or $\mathrm{T}$ in the wobble position. However, as shown in Fig. 5 , a number of exceptions were found where codons were used either more or less frequently than would have been expected, presumably reflecting the tRNA populations in these species. Knowledge of the preferred codon usage is useful for a variety of practical molecular biology applications.

Further analysis of the GroEL amino acid sequences of $B$. henselae and $B$. quintana was performed, comparing their intracellular signature sequences with those of $E$. 


\begin{tabular}{|c|c|c|c|c|c|c|c|}
\hline $\begin{array}{c}\text { Amino } \\
\text { acid }\end{array}$ & Codon & $\mathrm{Bq}$ & Bh & & $\underset{\text { acid }}{\text { Amino }}$ & Codon & $\mathrm{Bq}$ \\
\hline Phe & TTT & 5 & 7 & & Tyr & TAT & 3 \\
\hline Phe & TTC & 5 & 3 & & Tyr & TAC & 2 \\
\hline Leu & TTA & 3 & 4 & $\downarrow$ & Och & TAA & 1 \\
\hline Leu & TTG & 18 & 14 & $\uparrow$ & Amb & TAG & 0 \\
\hline Leu & CTT & 11 & 13 & & His & CAT & 0 \\
\hline Leu & CTC & 9 & 9 & & His & CAC & 1 \\
\hline Leu & CTA & 1 & 0 & $\downarrow$ & Gln & $\mathrm{CAA}$ & 10 \\
\hline Leu & CTG & 1 & 3 & & Gin & CAG & 7 \\
\hline lle & ATT & 23 & 24 & & Asn & AAT & 20 \\
\hline $\mathrm{He}$ & ATC & 17 & 15 & & Asn & $\mathbf{A A C}$ & 5 \\
\hline $\mathrm{Ile}$ & ATA & 0 & 0 & $\downarrow$ & Lys & AAA & 33 \\
\hline Met & ATG & 17 & 16 & & Lys & AAG & 10 \\
\hline Val & GTT & 30 & 28 & & Asp & GAT & 24 \\
\hline $\mathrm{Val}$ & GTC & 3 & 8 & & Asp & GAC & 7 \\
\hline Val & GTA & 6 & 5 & $\downarrow$ & Glu & GAA & 43 \\
\hline Val & GTG & 15 & 15 & $\uparrow$ & Glu & GAG & 3 \\
\hline Ser & TCT & 8 & 7 & & Cys & TGT & 0 \\
\hline Ser & TCC & 3 & 5 & & Cys & TGC & 0 \\
\hline Ser & TCA & 1 & 3 & $\downarrow$ & Opa & TGA & 0 \\
\hline Ser & TCG & 3 & - & & $\operatorname{Trp}$ & TGG & 0 \\
\hline Pro & $\mathrm{CCT}$ & 9 & 8 & & Arg & CGT & 13 \\
\hline Pro & $\mathrm{CCC}$ & - & - & & Arg & CGC & 9 \\
\hline Pro & $\mathrm{CCA}$ & 7 & 8 & & Arg & CGA & 0 \\
\hline Pro & CCG & - & - & & Arg & CGG & 1 \\
\hline Thr & $\mathrm{ACT}$ & 10 & 6 & & Ser & AGT & 0 \\
\hline Thr & $\mathrm{ACC}$ & 4 & 8 & & Ser & AGC & 2 \\
\hline Thr & ACA & 11 & 13 & & Arg & AGA & 1 \\
\hline Thr & ACG & 5 & 4 & & Arg & AGG & 0 \\
\hline $\mathrm{Ala}$ & GCT & 35 & 35 & & Gly & GGT & 28 \\
\hline $\mathrm{Ala}$ & GCC & 7 & 8 & & Gly & GGC & 11 \\
\hline $\mathrm{Ala}$ & GCA & 23 & 22 & & Gly & GGA & 11 \\
\hline $\mathrm{Ala}$ & GCG & 8 & 7 & & Gly & GGG & 5 \\
\hline
\end{tabular}

Fig. 5. Codon usage in the groEL genes of $B$. quintana (Bq) and $B$. henselae (Bh).

$\downarrow$ Underlined and emboldened letters are the preferred codons in $E$. coli (Grosjean \& Fiers,

$\downarrow \quad$ 1982; de Boer \& Kastelein, 1986). The arrows indicate codons that are used more $(\uparrow)$ or less $(\downarrow)$ frequently than anticipated given the low $\mathrm{G}+\mathrm{C}$ content of the genomes (41.0 mol\% and $40.3 \mathrm{~mol} \%$, respectively) and groEL genes $(44.3 \mathrm{~mol} \%$ and $44.5 \mathrm{~mol} \%$, respectively) of $B$. henselae and $B$. quintana (Daly et al., 1993).

\section{5}

EC AQVGTISATSDETVGKLIAEA

Bq ........NGAAEI..M..D.

Bh ........NGAAEI..M..D.

$\mathrm{Bb}$...A....NGA.DI..M..D.

$\mathrm{Ba} \ldots \ldots . \mathrm{N}$-AKQI..M....

At .........NGERQI.LD....

$\mathrm{Hm}$... A. . . NG.KEI.NI.SD.

\begin{tabular}{|c|c|}
\hline \multicolumn{2}{|l|}{393} \\
\hline \multicolumn{2}{|r|}{$\begin{array}{l}495 \\
\text { DPTKVTRSALQYAASVA }\end{array}$} \\
\hline R..G....V... & ..V..V.....N...I \\
\hline R..G.. & $\ldots \mathrm{V}$ \\
\hline R..GS. . & N...I \\
\hline R..G....V... & ..V.V.T. \\
\hline .GS....V.... & ..V..V.T...N... \\
\hline GTSD..VN & ....V.T..LD..G \\
\hline
\end{tabular}

\section{0}

$R$. G ...V...

R..G....V....

R..GS....V....

$\ldots . . .$.

...GTSD. .VN...
511

DPTKVTRSALQYAASVA

..V..V.....N...I.

..V..V.........I.

..V..V.T...N...I.

....V.T..LD..G.

Fig. 6. Partial alignment of Hsp60 sequences from prokaryotic and eukaryotic species depicting signature sequences described by Gupta (1995). Asterisks identify sequence features that are uniquely shared between $\alpha$-purple bacteria and mitochondria. Dots indicate residues identical to those present in the top row. The dash at position 154 in the alignment identifies a gap introduced to maximize alignment. Ec, E. coli; Bq, B. quintana; Bh, B. henselae; Bb; B. bacilliformis; Ba, Brucella abortus; At, Agrobacterium tumefaciens; $\mathrm{Hm}$, human mitochondria.

coli, other $\alpha$-purple bacteria and human mitochondria (Fig. 6). These signature sequences are found exclusively in mitochondrial GroEL homologues and GroEL proteins of $\alpha$-purple bacteria (Gupta, 1995). Unlike $E$. coli GroEL, the GroEL sequences of B. quintana and $B$. benselae contain these intracellular signature sequences.

\section{DISCUSSION}

This study presents the first characterization of the heat shock response that we are aware of in Bartonella species. The finding that $B$. henselae and $B$. quintana exhibit a heat shock response was expected and is 
consistent with their respective life cycles, which involve both mammalian and ectoparasitic hosts. A significant heat shock response was not observed until the incubation temperature was raised above $37^{\circ} \mathrm{C}$, the normal mammalian core body temperature. A similar finding has been observed in other bacteria, including Brucella abortus (Lin et al., 1992) and Borrelia burgdorferi (Stamm et al., 1991), suggesting that factors in addition to temperature may be involved in regulating heat shock protein expression in Bartonella species.

The heat shock response is highly conserved in prokaryotes and is thought to represent adaptation to the stressful environment of the mammalian host. The heat shock response of $B$. henselae and $B$. quintana involved expression upregulation of GroEL, a $10 \mathrm{kDa}$ protein (presumed to be GroES), and a $70 \mathrm{kDa}$ protein (presumed to be the molecular chaperonin DnaK). Both Bartonella species also upregulated expression of a fourth major heat shock protein (Mhsp4), with an apparent molecular mass in the range $17-20 \mathrm{kDa}$, a pattern similar to that seen in Brucella abortus (Lin et al., 1992). The descrepancy in molecular masses of Mhsp4 suggests that elucidation of its identity and function may be important in understanding differences in the pathobiology of these two Bartonella species. In this regard, it is interesting to note that immunoblots of $B$. henselae and $B$. quintana probed with $B$. henselaespecific antiserum detect a prominent $17 \mathrm{kDa}$ antigen which is unique to $B$. henselae (data not shown). This immunoreactive $17 \mathrm{kDa}$ antigen, described by Anderson et al. (1995), may be the same protein as the $B$. henselae Mhsp4 we describe in this study.

After identification of $B$. henselae DNA (Relman et al., 1991) and the subsequent isolation of the organism from patients with bacillary angiomatosis (Regnery et al., 1992; Welch et al., 1992), B. henselae was initially assigned to the genus Rochalimaea. At that time, only two other members of the Rochalimaea genus had been described, $R$. quintana (the agent of trench fever) and $R$. vinsonii (Weiss \& Moulder, 1984). Subsequent phylogenetic analysis based on rRNA sequences resulted in unification of the genera Bartonella and Rochalimaea (Brenner et al., 1993). In this study we report the phylogenetic analysis of alignments of the groEL gene sequences of $B$. quintana, $B$. henselae and other related bacteria. We found that $B$. quintana and $B$. henselae form a monophyletic group with $B$. bacilliformis, confirming their taxonomic assignment to the genus Bartonella. These results suggest that groEL sequences would serve as an alternative to rRNA for determining the relatedness of the other Bartonella species. Another potential use of comparative analysis of Bartonella groEL sequences is to identify variable regions which would allow design of species- and/or genus-specific oligonucleotide probes. Oligonucleotide probes based upon groEL gene sequences have been found to be useful for species identification of staphylococci (Goh et al., 1996).

Intracellularity is an essential aspect of the interaction of Bartonella species with their mammalian hosts
(Reynafarje \& Ramos, 1961; Kordick \& Breitschwerdt, 1995). Bartonella species have also been shown to invade a number of cultured human cell types (McGinnis Hill et al., 1992; Batterman et al., 1995). Recently, the B. bacilliformis genes involved in mediating erythrocyte invasion have been identified (Mitchell \& Minnick, 1995). These phenotypic and molecular characterizations are consistent with the phylogenetic analysis of rRNA and groEL sequences which indicate that Bartonella species are members of the $\alpha$-purple subdivision of Gram-negative bacteria, organisms found to live intracellularly within eukaryotic plant or animal cells. Analysis of bacterial groEL gene sequences has been of particular interest because, unlike rRNA genes, homologues are present in eukaryotic organelles such as mitochondria and chloroplasts. Global alignment of prokaryotic and eukaryotic GroEL sequences revealed that GroEL sequences of $\alpha$-purple bacteria, including $B$. bacilliformis, are more closely related to those of mitochondrial homologues than they are to GroEL sequences of other bacteria, such as E. coli (Gupta, 1995). A number of GroEL signature sequences have been identified that are uniquely shared by members of $\alpha$-purple bacteria and their mitochondrial homologues (Gupta, 1995). The present study demonstrates that the GroEL sequences of $B$. quintana and $B$. henselae also contain these intracellular signature sequences (Fig. 6). This evidence for the genetic relatedness of B. quintana and $B$. henselae to intracellular bacteria and eukaryotic organelles confirms the importance of intracellularity in the biology of these organisms.

\section{ACKNOWLEDGEMENTS}

This work was supported by funding from a UCLA School of Medicine Frontiers of Science Award (D.A.H.).

\section{REFERENCES}

Anderson, B., Lu, E., Jones, D. \& Regnery, R. (1995). Characterization of a 17-kilodalton antigen of Bartonella benselae reactive with sera from patients with cat scratch disease. J Clin Microbiol 33, 2358-2365.

Batterman, H. J., Peek, J. A., Loutit, J. S., Falkow, S. \& Tompkins, L. S. (1995). Bartonella henselae and Bartonella quintana adherence to and entry into cultured human epithelial cells. Infect Immun 63, 4553-4556.

Birtles, R. J., Harrison, T. G., Saunders, N. A. \& Molyneux, D. H. (1995). Proposals to unify the genera Grahamella and Bartonella, with descriptions of Bartonella talpae comb. nov., Bartonella peromysci comb. nov., and three new species, Bartonella grahamii sp. nov., Bartonella taylorii sp. nov., and Bartonella doshiae sp. nov. Int J Syst Bacteriol 45, 1-8.

de Boer, H. A. \& Kastelein, R. A. (1986). Biased codon usage: an exploration of its role in optimization of translation. In Maximizing Gene Expression, pp. 225-285. Edited by $\mathrm{W}$. Reznikoff \& L. Gold. Stoneham, MA : Butterworth.

Brenner, D. J., O'Connor, S. P., Winkler, H. H. \& Steigerwalt, A. G. (1993). Proposals to unify the genera Bartonella and Rochalimaea with descriptions of Bartonella quintana comb. nov., Bartonella vinsonii comb. nov., Bartonella henselae comb. nov., and Bartonella elizabethae comb. nov., and to remove the family 
Bartonellaceae from the order Rickettsiales. Int J Syst Bacteriol 43, 777-786.

Chomel, B. B., Kasten, R. W., Floydhawkins, K. \& 7 other authors (1996). Experimental transmission of Bartonella benselae by the cat flea. J Clin Microbiol 34, 1952-1956.

Daly, J. S., Worthington, M. G., Brenner, D. J., Moss, C. W., Hollis, D. G., Weyant, R. S., Steigerwalt, A. G., Weaver, R. E., Daneshvar, M. I. \& O'Connor, S. P. (1993). Rochalimaea elizabethae sp. nov. isolated from a patient with endocarditis. J Clin Microbiol 31, 872-881.

van Eden, W., Thole, J. E. R., van der Zee, R., Noordzij, A., van Embden, J. D. A., Hensen, E. J. \& Cohen, I. R. (1988). Cloning of the mycobacterial epitope recognized by $\mathrm{T}$ lymphocytes in adjuvant arthritis. Nature 331, 171-173.

Goh, S. H., Potter, S., Wood, J. O., Hemmingsen, S. M., Reynolds, R. P. \& Chow, A. W. (1996). Hsp60 gene sequences as universal targets for microbial species identification: studies with coagulase-negative staphylococci. J Clin Microbiol 34, 818-823.

Gor, D. \& Mayfield, J. E. (1992). Cloning and nucleotide sequence of the Brucella abortus groE operon. Biochim Biophys Acta 1130 , 120-122.

Grosjean, H. \& Fiers, W. (1982). Preferential codon usage in procaryotic genes: the optimal codon-anticodon interaction energy and the selective usage in efficiently expressed genes. Gene 18, 199-209.

Gupta, R. S. (1995). Evolution of the chaperonin families (Hsp60, Hsp10 and Tcp-1) of proteins and the origin of eukaryotic cells. Mol Microbiol 15, 1-11.

Higgins, D. G. \& Sharp, P. M. (1988). Clustal: a package for performing multiple sequence alignment on a microcomputer. Gene 73, 237-244.

Higgins, J. A., Radulovic, S., Jaworski, D. C. \& Azad, A. F. (1996). Acquisition of the cat scratch disease agent Bartonella henselae by cat fleas (Siphonaptera: Pulicidae). J Med Entomol 33, 490-495.

Knobloch, J. \& Schreiber, M. (1990). Bb65, a major immunoreactive protein of Bartonella bacilliformis. Am J Trop Med Hyg 43, 373-379.

Kordick, D. L. \& Breitschwerdt, E. B. (1995). Intraerythrocytic presence of Bartonella henselae. J Clin Microbiol 33, 1655-1656.

Laemmli, U. K. (1970). Cleavage of structural proteins during the assembly of the the head of bacteriophage T4. Nature 227, 680-685.

Lamb, J. R., Bal, V., Mendez-Samperio, P., Mehlert, A., So, A., Rothbard, J. B., Jindal, S., Young, R. A. \& Young, D. B. (1989). Stress proteins may provide a link between the immune response to infection and autoimmunity. Int Immunol 1, 191-196.

Lin, J., Adams, L. G. \& Ficht, T. A. (1992). Characterization of the heat shock response in Brucella abortus and isolation of the genes encoding the GroE heat shock proteins. Infect Immun 60, 2425-2431.

McGinnis Hill, E., Raji, A., Valenzuela, M. S., Garcia, F. \& Hoover, R. (1992). Adhesion to and invasion of cultured human cells by Bartonella bacilliformis. Infect Immun 60, 4051-4058.

Marck, C. (1988). DNA Strider: a "C" program for the fast analysis of DNA and protein sequences on the Apple Macintosh family of computers. Nucleic Acids Res 16, 1829-1836.
Mayhew, M. \& Hartl, F.-U. (1996). Molecular chaperone proteins. In Escherichia coli and Salmonella: Cellular and Molecular Biology, 2nd edn, pp. 922-937. Edited by F. C. Neidhardt and others. Washington, DC: American Society for Microbiology.

Mitchell, S. J. \& Minnick, M. F. (1995). Characterization of a twogene locus from Bartonella bacilliformis associated with the ability to invade human erythrocytes. Infect Immun 63, $1552-1562$.

Norman, A. F., Regnery, R., Jameson, P., Greene, C. \& Krause, D. C. (1995). Differentiation of Bartonella-like isolates at the species level by PCR-restriction fragment length polymorphism in the citrate synthase gene. J Clin Microbiol 33, 1797-1803.

Rao, V. B. (1994). Direct sequencing of polymerase chain reactionamplified DNA. Anal Biochem 216, 1-14.

Regnery, R. L., Anderson, B. E., Clarridge, J. E., III, RodriquezBarradas, M. C., Jones, D. C. \& Carr, J. H. (1992). Characterization of a novel Rochalimaea species, $R$. henselae sp. nov., isolated from blood of a febrile, human immunodeficiency virus-positive patient. J Clin Microbiol 30, 265-274.

Relman, D. A., Falkow, S., LeBoit, P. E., Perkocha, L. A., Min, K.-W., Welch, D. F. \& Slater, L. N. (1991). The organism causing bacillary angiomatosis, peliosis hepatis, and fever and bacteremia in immunocompromised patients. $N$ Engl J Med 324, 1514.

Reynafarje, C. \& Ramos, J. (1961). The hemolytic anemia of human bartonellosis. Blood 17, 562-578.

Sambrook, J., Fritsch, E. F. \& Maniatis, T. (1989). Molecular Cloning: a Laboratory Manual, 2nd edn. Cold Spring Harbor, NY: Cold Spring Harbor Laboratory.

Schwartzman, W. (1996). Bartonella (Rochalimaea) infections: beyond cat scratch. Annu Rev Med 47, 355-364.

Segal, G. \& Ron, E. Z. (1993). Heat shock transcription of the groESL operon of Agrobacterium tumefaciens may involve a hairpin-loop structure. J Bacteriol 175, 3083-3088.

Stamm, L. V., Gherardini, F. C., Parrish, E. A. \& Moomaw, C. R. (1991). Heat shock response of spirochetes. Infect Immun 59, $1572-1575$

Weiss, E. \& Moulder, J. W. (1984). Genus II. Rochalimaea (Macchiavello 1947) Krieg 1961, 162 ${ }^{\mathrm{AL}}$. In Bergey's Manual of Systematic Bacteriology, vol. 1, pp. 698-701. Edited by N. R. Krieg \& J. G. Holt. Baltimore: Williams \& Wilkins.

Welch, D. F., Pickett, D. A., Slater, L. N., Steigerwalt, A. G. \& Brenner, D. J. (1992). Rochalimaea henselae sp. nov., a cause of septicemia, bacillary antiomatosis, and parenchymal bacillary peliosis. J Clin Microbiol 30, 275-280.

Wong, M. T., Thornton, D. C., Kennedy, R. C. \& Dolan, M. J. (1995). A chemically defined liquid medium that supports primary isolation of Rochalimaea (Bartonella) henselae from blood and tissue specimens. J Clin Microbiol 33, 742-744.

Young, D. B., Mehlert, A. \& Smith, D. F. (1990). Stress proteins and infectious diseases. In Stress Proteins in Biology and Medicine, pp. 131-165. Edited by R. I. Morimoto, A. Tissieres \& C. Georgopoulos. Cold Spring Harbor, NY: Cold Spring Harbor Laboratory.

Received 1 May 1997; accepted 9 May 1997. 